https://doi.org/10.31470/2706-7904-2020-15-26-29

\title{
SPECIALIZATION OF MENTAL FUNCTIONS IN THE PROCESS OF LANGUAGE ACQUISITION
}

\section{Спеціалізація ментального функціонування в процесі набуття мовних знань}

\author{
Iryna Vakulyk \\ Ph.D. in Philology, Assistant Professor \\ National University of Life and Environmental Sciences of Ukraine \\ vakulyk@ukr.net \\ https://orcid.org0000-0002-4812-7719
}

\begin{abstract}
In the abstract specialization of mental functions in the process of language acquisition described. The hypothesis of our study was to find out how strong was the dynamics of influence on the formation of mental structures, on value orientations, worldview, life experience of homo sapiens. The study used the method of explication in order to reveal a new concept globalization as reflection of knowledge about language.
\end{abstract}

Key words: language, mental functions, mental structures, globalization, professional training, process of language learning.

\section{Introduction}

The studying of ancient languages, of which Latin is of no small importance, at the current stage of development of higher education covers not only actual problems of teaching foreign languages, but also becomes a component of the professional training of future professionals.

\section{Methods and Techniques of the Research}

The hypothesis of our study was to find out how strong was the dynamics of influence on the formation of mental structures, on value orientations, worldview, life experience of homo sapiens. The study used the method of explication in order to reveal a new concept globalization as reflection of knowledge about language. The method is never invariably frozen; it must be adjusted when the teaching conditions change. 


\section{Results}

According to the American methodologist, professor of the University of Chicago Peter Hagboldt, teaching foreign languages can pursue practical and educational goals, the choice of which depends on objective conditions and on the duration of the course. The method, in his opinion, is a set of techniques aimed at achieving a certain goal within a certain period of time in the presence of certain teaching aids, taking into account the age and general development of students, as well as schools and society. The method is never invariably frozen; it must be adjusted when the teaching conditions change (Кашина, 2006; 21). The main goal of a linguistic teacher in the classroom is to simplify the process of language learning as much as possible. After all, it is the teacher who acts as a predictor, since he must provide for possible error options in solving predetermined tasks, as well as find ways to overcome them. «It is much easier to succeed when each individual task is considered as part of the general task, and not as an independent one ... When a student does not know the ultimate goal of training, ... he resorts to a relatively easy way to satisfy his requirements and verbally memorizes material either from a textbook or ... as explained by the teacher» (Hagboldt, 1963; 56-57).

The realization that the general task is much wider, involuntarily and subconsciously makes students concentrate their efforts on the subject under study (Balalaieva, 2014; Vakulyk, 2013). The psychologist Bergson believed that the main function of the intellect is rubrication. Here are his words: «Intelligence is the ability to find the interconnection of phenomena, the ability to grasp their recurrence, and, if necessary, produce it» (Bergson, 1979: 59).

«To explain something is to see in the new and unforeseen elements of the old and familiar, organized in a new order» (Maslou, 1999: 181). The essence of the language is not in the use of any method of communication, but in the use of fixed ... it means that something tangible - a spoken word, picture, gesture, or whatever - could trigger an idea of something else. When this happens, the tangible can be called a «associations sign» or «symbol», and what the idea is about is «significant» (Panov, 1983: 66). That's, V.A. Zvegintsev calls language a means of mentally dividing the world around us into discrete concepts, as well as an instrument for classifying these concepts. According to F. de Saussure, the word as a linguistic sign is «two-sided psychic essence», which rests on the inextricable connection between the concept and its acoustic image. Wherever a new word came to a person - in oral conversation, from the pages of a book or newspaper - in all cases it will be stored in memory in the form of a sound image. This image at any time can be imagined mentally (through the so-called «internal speech») or reproduced aloud. And invariably at the same moment an abstract concept pops up in memory that corresponds to a given acoustic image (Panov, 1983: 68-69). 
The natural language of a person carries out semiotic modeling and thereby serves as a universal semiotic matrix on which to build a virtually unlimited number of a wide variety of familiar or informational systems (Panov, 1983: 88). The specialization of mental functions in the process of development history is accompanied by a complication of the «anatomy» of the psychophysical activity of a living creature: activity is divided into actions, and actions into operations (A.N. Leontiev). Therefore, each level of the mental has its own qualitatively different content, determined not by simply summing up the information of the lower floors, but by the type of tasks to be performed to ensure the practical life of the body (Zhol, 1990: 54).

Acquiring receptive language skills is incomparably easier than acquiring reproductive language skills. We can learn to read yet not knowing how to express our thoughts (Hagboldt, 1963: 39). Thus, it can be argued that there is an interdependence of various types of speech activity - listening, reading aloud, reading to oneself, speaking, writing. Consequently, there is a merger of certain types of speech activity into a single whole.

To understand a foreign language ... knowledge of its phonetics and vocabulary is completely insufficient. Without knowledge of grammar, we can only approximately understand the most simple phrases. For the deaf-mute, the sound language in which the people of his homeland communicate speaks in the same capacity as ... a language for a Frenchman or an Englishman. And if the translation of lexical concepts from the spoken language into the language of the deaf-mute should cause noticeable difficulties, then these difficulties grow immeasurably when we encounter the problem of gesture expression of grammatical categories (gender, case, time, etc.) (Panov, 1983: 94).

Hearing does not include operations that would not go into speaking; but speaking includes all the operations involved in listening, plus the logical operations of viewing the future and choosing. The logistics of speaking is somewhat reminiscent of an amateur game of chess, where it is allowed to «take moves back» and where you can often not see the situation on the chessboard (not even notice that the king has been declared a check!) (Hokkett, 1965: 165).

All languages have methods of limiting regression, methods of preserving depth, as well as methods that make it possible to circumvent the limitation of the amount of memory in order to preserve expressive power (Ingve, 1965: 138). Psychologists have measured what is called the amount of immediate memory. We are able to remember at a glance and correctly reproduce approximately seven decimal digits taken at random, about seven unrelated words, about seven names. This has long been studied at Harvard University by J. Miller (Ingve, 1965: 127).

The largest number of units that can be perceived, remembered and recreated by an ordinary person after the first presentation is approximately $7 \pm 2$. Thus, the Miller magic 
number indicates the number of units of information held in memory. And although forgetting is undesirable in learning, researchers say: the largest percentage of forgetting falls on the first 48 hours after perceiving or memorizing the material. Therefore, a single individual must develop its own system of memorization and reproduction of information.

According to the law of Yerks-Dodson («optimum motivation»), to achieve success requires an optimal (or, more simply put, moderate, average) level of motivation. As a result of experiments conducted on animals, and later on people, it turned out that weak motivation is not enough for success, but excessive motivation is harmful because it generates unnecessary excitement and fussiness (when people worked «through the sleeves» for a purely symbolic gain, and the results were not high; and as the rewards increase, so does enthusiasm; the results accordingly improve).

Optimum motivation can be achieved in the process of forming the goal. This contributes to attention. Thanks to him, consciousness focuses on a specific object. In the dynamics of attention, the ability to set a goal is of utmost importance. The setting and constant refinement of the goals of activity arouses, maintains and switches attention (Bogoslovskyi, 1981: 155). Attention indicates the purpose of possible practical actions. To make them possible from the possible, the goal must be presented as a task, i.e. must be recognized, appreciated and appropriately expressed. The formulation of the problem and its phased solution takes on the cognitive function of linguistic consciousness (Zhol, 1990: 13).

\section{Conclusion}

This way, in the process of learning the ancient language and the learning process, it is necessary to consider the following:

(1) there is a complex mechanism of perception and understanding of language units, which can cause possible cases of bias in the adequacy of the understanding of the text;

(2) in practice language, stereotypes of thinking and stereotypes of linguistic turnarounds may arise; therefore, an exact setting on a logical, rational perception of a word is necessary;

(3) the possibility of using combined types of building classes entails focusing on specific issues (e.g. phonetic norms, morphological structure of the language, structural and semantic features of phrases, semantic and functional characteristics of the word, etc.). Thanks to the language, we arm our consciousness, which allows us not only to limit ourselves to acts of communication, but also to develop a mechanism for participation in the socio-cultural environment. 